\title{
Local Balancing System from the Business Model Canvas Perspective
}

\author{
Bożena Ewa Matusiak ${ }^{1, a}$ \\ ${ }^{1}$ University of Lódź, Faculty of Management, Department of Computer Science, Matejki 22/26, 90237 Lódź, Poland
}

\begin{abstract}
The paper presents an overall view of the business model (BM) for the e-balance system for: balancing energy production and consumption in energy efficient, smart neighbourhoods (the e-balance project, FP7SMARTCITIES-2013) along with its functionalities, based upon the Osterwalder's canvas methodology. Additionally, this is the second, after two years of work, more incisive evaluation of the BM from the user's and demo site's perspective (Bronsbergen, the Netherlands). The aim of this paper is to present results and assess the above mentioned BM in the face its commercialisation and applicability to Europe.
\end{abstract}

\section{Introduction}

Smart grids, dispersed energy resources (DER) development, active demand response management (ADRM) and energy flexibility (EF) on the power market - these are the main elements which play a critical role in understanding of the energy policy ambitions in the future European power system [1, 2]. Demand response [3, 4], a need for more energy flexibility and better use of them in local destinations (smart neighbourhoods) trigger many innovative projects, platforms/applications, as well as new business model approaches and propositions [5].

The e-balance project proposes a new system on the energy market with a large number of prosumers who will not only consume the energy, but mainly produce and save it depending on the market and price /incentives conditions [6, 7]. The available energy capacity (i.e. energy flexibility) for demand response can be executed by dynamic management and a special Triana algorithm [8]. The new, most important role in this system will be played by market-makers, referred to as aggregators. So far the aggregator is not a clearly identifiable electricity market actor. Such a role and areas of its responsibilities are still in development $[9,10]$.

The e-balance system/platform proposes one of the solutions to involving the aggregators into the bottom-up processes of the energy flexibility aggregation (in comparison with [13]).

This paper presents the current state of the e-balance system and its business model's picture [6] using the Osterwalder's canvas after two years of project work.

\subsection{Tool and method used}

Within the last decade, the Osterwalder's business model canvas approach [11] has become a very popular tool

\footnotetext{
${ }^{\mathrm{a}}$ Corresponding author: bmatusiak@pocztawz.uni.lodz.pl
}

and method of thinking not only in the internet start-ups, but also in the energy market and smart grid projects. In the area of innovative ideas, it is hard to find a more adequate tool for the first BM assessment, systematic recognition and answering the resultant main questions: what the system will be, to whom it will apply and where the added values are. Investors are not eager to trust in an overall description of new systems or technology without a methodological approach or even a detailed business plan.

Many complementary analyses and first step studies might be used in order to find the effective methods of building the reliable systematic BM framework. These methods include: the analysis of market competition / suppliers / manufacturers and users, SWOT analysis, business or use cases descriptions of needs, KPI's definition for adequate BM validation [6], deep insight analysis after a feedback from the users, followed by the first assessment of risk analysis and a business plan.

The most innovative BMs in several European projects such as: Sustainable Places, CityOpt, Besos, Optimus, Ambassador, Indicate etc. are considered to have used mainly the Osterwalder's tool for structured BM specification [12].

The earlier mentioned BM Osterwalder's canvas consists of several blocks. Each block needs additional analysis and studies to be answered, including: Customers' segmentation, Value proposition, Dissemination channels, Customers' relations, Revenue / financial, Key resources, Key activities, Key partners and Cost structure description. 


\section{Business Model}

The next part of this paper presents the prepared e-balance BM description according to the above mentioned nine blocks with an overall technical description of the system.

\subsection{Key activities' description}

The end user (mainly prosumers with the smart meter, smart devices, and the dedicated GUI at home) is the first and the most important actor in the e-balance system. The Customer Management Unit (CMU) is an additional device provided by the e-balance system to the user/prosumer, which allows them to interact with the system in a technical sense [14]. It will function as the energy manager, data hub and (tele) communication portal (See Fig. 1.)

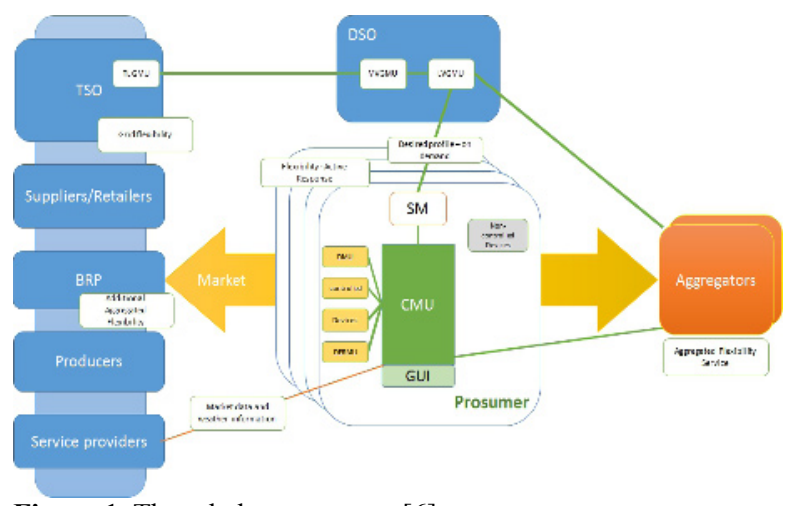

Figure 1. The e-balance system. [6]

The CMU will be connected to the Smart Meter (SM) for the local data analysis purposes. It may be connected to the local LAN via a direct connection or via WLAN. This connection will be used to acquire additional information for data analysis. After the initial, physical connectivity, other devices that need to be directly connected can be attached (DMUs for many smart devices (IEDs) and sensors). The end user may also possess the devices that are not connected to the CMU. Such devices will not be operable by steering signals from the system, but their demand will be estimated by the system. By using the GUI, the end user can set the initial system parameters (home scenario/ strategy). If the DER (micro generation) was connected as a set of PV panels, the typical characteristics can be delivered to the system.

The end-user of the e-balance system will have a CMU used to also predict (using information from the weather forecast agency) [14], monitor and control the energy usage and/or production. The CMU will gather all the desired energy usage of Intelligent Energy Devices (IEDs) and dispersed generation and saving (DER installations/batteries) in the shape of power profiles.

Subsequently, through the aggregators' activities, the users' power profiles are combined with a prediction of the energy usage of all the other devices connected to the local installation within the smart area.
The resulting aggregated profile will be communicated to the DSO. This will be repeated every 15 minutes; sending out the predicted aggregated power profile for the next 24 hours and sent to the DSO by the aggregator.

The role of aggregators is to aggregate and to incentivise end users to react to the DSO/Triana algorithm signals. The DSO may respond with a general request to reduce or increase the energy exchange with the grid in either direction (usage or feed-in) for each of the 15-minute intervals. Using incentives (technical as a steering signals), the aggregator is supporting the DSO with an information exchanging process and the calculation of benefits (financial) for each customer involved in this process. The aggregator's CMU will negotiate with the smart devices and with the user's CMU to determine to what extent it is possible to comply with the general DSO request [14]. A measure determined by the CMU (on the aggregator's side) will indicate how well it can assist the DSO. This single number will be delivered back to the DSO, which will then again inform the aggregator's whether or not the newly negotiated power profile should follow the originally sent profile.

The DSO can provide and maintain the e-balance main infrastructure in the user's home, but this is not at all obvious. The CMU's, DMU's and SM can be provided by other market actors. The DSO will facilitate the controlled balancing of energy, provide information and access to the energy market, as well as assist all stakeholders.

The aggregator (that can also be the ESCO company) supports and aggregates all financial processes and data in cooperation with retailers, which will prepare the final settlements. The most important mechanism on how to settle the costs and revenues will be hidden in the price and incentives mechanisms proposed under a win-win strategy for all sides of the contract [6]. It is indeed interesting how to go about preparing and matching a system of tariffs for each of the groups of aggregated users. This is separated area of next researches in this project.

In the low voltage grid, the most significant component of the e-balance infrastructure will be the Low Voltage Grid Management Unit (LVGMU). The LVGMU will request every CMU of the connected aggregators or end users' CMUs to send out a power profile with a 15-minute interval (covering a total time span of 24 hours). It is likely that not every connection to the low voltage grid will be equipped with a CMU. Hence, the LVGMU will have to make a prediction of the energy exchange at the particular points of connection. The predictions and communicated CMU power profiles are gathered to form a "neighbourhood profile". This profile represents the unadjusted, expected power usage for the following 24 hours (in this sense it corresponds with Day Ahead Market and Intraday Market).

The newly formed neighbourhood profile will be compared to a pre-programmed "desired profile". At the beginning, this profile will represent a default setting and might be, for instance, a completely flat profile. The absolute value of this profile is the subject 
of the e-balance system research. The desired profile will be influenced by the local grid limitations and requests from other management units. During or after the negotiation phase, the LVGMU will perform a technical "rationality check" by using the supplied profile as an input to the electrical load flow. This is a calculation that will show whether grid components are overloaded and if the grid voltages remain within the grid code limits.

The result of the comparison will be a power profile, indicating at which times there will be an energy shortage or surplus and how large it will be. The CMUs will respond with a single number specifying how well they are capable of assisting in solving the shortage or consuming the surplus. The LVGMU will rank these responses and select the CMUs that together can reduce the difference profile in the most efficient way.

All remaining difference profiles are communicated by a group of LVGMUs, upwards to the Medium Voltage Grid Management Unit (MVGMU). The MVGMU will go through a similar process as the one described above.

Any remaining differences after these negotiations will be communicated upwards to the Top Level Grid Management Unit (TLGMU). This TLGMU will provide balance amongst the MVGMUs, large centralised power plants, and the grid connections to the neighbouring regions (interconnectors) [14].

It is important to recognise that, on a conceptual level, the centralised power plants will be reduced to an imbalance functionality and the transport grid will only be used when Distributed Energy Resources (DER) are insufficient to deliver the desired power to a given region. In practice, considering the currently low amounts of DER and low flexibility of loads and generators in most regions, the centralised power plants will be retained to have a peak and base load functionality.

It should be noted that in the e-balance system, the aggregator works on behalf of the aggregated customers and can offer flexibility for their customers towards balance responsible parties (BRPs) as an additional service.

The BRP might want the end users (by aggregators) to reduce energy consumption, or increase production in order to compensate for the lack of production elsewhere, thus enforcing better energy availability elsewhere (on the Intra Day Market). In such a case, the user's/aggregator's CMU will not aid the DSO by complying with the LVGMU's request, but instead will additionally comply to the BRP's request. As such, the BRP and DSO will both provide incentives to influence the behaviour of the customers, but these incentives are not necessarily the same.

The settlement and invoicing will be prepared according to the measures taken from the smart meters and will correspond to the contracts made with the aggregators and retailers/suppliers. The aggregators together with suppliers offer the additional services as a "demand response flexibility" on the market and are also responsible for the system of prices and incentives [6, 7].-This is the most important mechanism for achieving a satisfactory level of cooperation with end users.
In this sense, the key activity is to provide the energy flexibility on the market. The four actors mainly involved in this process are: the end user, the aggregators of endusers, the DSOs and the retailers.

\subsection{Customers' segmentation}

The e-balance platform is dedicated to the prosumers - as the main users of the system and to those who are involved and will have any interactions with the dynamic energy management within the whole, single energy system.

However, prosumers are not the only ones who can have a contract to use the e-balance system. Depending on the features, retail customers, RES/DER owners, commercial users, customers who are interested in energy efficiency and decreasing costs, city municipalities or real estate owners, can also be the main consumers of our product. They can focus on saving money and reaching the high energy efficiency and security of the energy supply (by using the new energy system and smart appliances or sensors, home batteries, smart cars). They are willing to provide feedback regarding the service and to adapt an e-balance system into their premises $[15,16]$.

They have their own smart devices, as well as the contract for the direct devices control with the e-balance direct provider (which can be the aggregator party).

\subsection{Value proposition}

The deeper value proposition analysis for all stakeholders was prepared during project work and is visualized in the Fig. 2 , described in detail in [6].

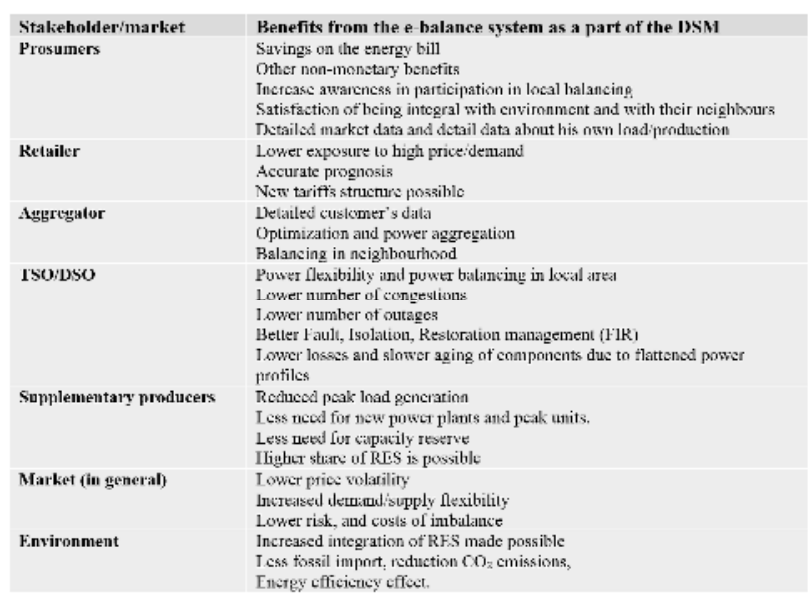

Figure 2. Benefits for market roles and the environment when e-balance is utilised.

A user wants to receive lower bills for the energy consumption and to be satisfied about being ecological and efficient in her/his local environment. The neighbourhoods will become more cooperative and aware in terms of their energy saving.

The DSO has a more stable and optimal power flow in part of the grid, with a minimum cost of its 
maintenance, losses and faults' decrease. The DSO also has quality benefits from grid monitoring and maintenance service offered in the e-balance system.

For other partners who have a greater demand for their products and services, sometimes this can even mean a new service or business for them. There is a possibility of increasing local activities on the basic, neighbourhood level.

Third parties - aggregator/retailers or ESCOs - benefit from increasing the energy efficiency in the area of their activity.

A Smart City has a modern system for the energy optimisation which will develop in a scalable/fractal way with benefits for the environment of future generations.

The main value of the e-balance system is to provide the flexibility in the energy exchange with the grid. At request, the amount of power drawn from the grid can be reduced or increased (both in amplitude and direction i.e. withdrawal or feed-in). It is solely the users' strategies that determine the amount and shape of the flexibility provided.

\subsection{Dissemination channels}

Website and internet apps, mobile apps, hot-lines, calls with experts, as well as in-home display(GUI) will be the main channels for consumer/prosumer communication and their feedback signals from the users $[17,18]$.

- GUI (in home display with dedicated apps) meaning all types of devices providing graphics visualisation of the energy consumption and production data on screen, smartphone apps etc.

- Website with access to the e-balance system and modules.

- Machine to machine communication for operations and technical system realisations (through the dispersed services/modules of the e-balance system).

- Internet infrastructure with wireless communication (all telecommunication stack).

- Informative correspondence. It refers to the information regarding all important data given to the users (e-books or newsletters, on line and real time information, on line bills).

\subsection{Customer relations}

All relationships between partners will be based on understandable contracts, cooperation and trust. The owner such as the DSO and the aggregator/ the retailer will be the main providers of services (the energy balancing and grid resilience). They can have a cooperation contracts for balancing service performance, where the aggregator/the retailer will work on behalf of the DSO in the area of the e-balance functionalities. The part of the system such as the CMU tools can be distributed by retailers or technical providers. The retailers can use the CMU installations for additional auxiliary services preparation as well. It means that the retailers can have their own system of price incentives, different from the aggregators' incentives.

As a main mechanism for the e-balance system, a set of financial mechanisms will be delivered along with help/guidance on every level. Furthermore, some gamification methods, non-monetary incentives and feedback systems are also considered, especially at the beginning (during the project's time and testing). The systems of tariffs, as well as incentives will be chosen for each type of users' activity in the e-balance system. The right choice will depend on the in-lab testing, the detailed analysis of the previous load profile and the type of strategy savings. Overall, finding the winwin strategy of rewards for each participant of the system was the most crucial goal. Although, such analysis has been done [6], the basic conflict of interests was also identified among the roles of the aggregator, retailer and the DSO.

\subsection{Revenue}

In the first stage of the e-balance system (for MVP), the revenue model is thought to be a supplemental payment for given values as a transaction fee. The end user will also pay for additional apps only when using them. Moreover, the licence fee is also re-considered (yearly or monthly). The application for the e-balance system and service maintenance will have a fixed monthly charge (added to the bill) [6]. The in-home display will be provided as a consumer leasing system of payment. It can be proposed to the system owner to have the additional revenues on the adverts of products recommended as compatible with the system on the website. A multiple flow schedule, in which the monthly fee, extra rewards for customers, long-term contracts and system of incentives, is considered.

The decision about the final recommendation will be made after the in-lab testing.

\subsection{Key resources}

Key resources were considered on every level of the e-balance system/apps, as well as within the technical grid infrastructure (on LV/MV levels). The detailed list of appliances/resources was prepared in [19]. A technical grid specification was listed in the e-balance deliverables: $[14,20]$. This is on the assumption that the smart meter and the Internet access had been installed in the user's house earlier. Instead of developing a DMU on our own, the main focus was put on standard solutions which improved the system scalability and applicability. The same concerned the communication technologies to be used within the Home Area Network (HAN) that connect the DMUs to their corresponding CMU. The CMU is equipped with several communication modules or gateways supporting interoperability.

In terms of human recourses, it was assumed that a professional staff, equipped with necessary skills corresponding to the BM needs, will be involved. 
In such a case, the engineers will operate and maintain the e-balance resources and web applications, whereas the marketing and sales staff will co-create the best vision of the services and the added value for the customers.

Apart from all of the above mentioned items, the financial resources are the most important. Financing should be available considering this business model, which was developed regarding increasing grid flexibility. Naturally, the first investments funds will be provided by DSOs and other cooperative partners, as a joint venture capital. The accepted model of reimbursement should guarantee a profit and return on the investment.

\subsection{Key partners}

During the project work, ten different stakeholders were selected and described as the most important actors along the value chain (Fig 2) [6]. Their current and future role has been proposed and described. The DSO is a main coordinator and a market facilitator for the e-balance platform. The relations among the end users- aggregatorsDSO and retailers are crucial for balancing and the financial processes flow.

\subsection{Cost structure}

Today, the actual investment costs in Bronsbergen can be assessed only in regards to the physical resources. This had been incorporated into the planning of the project. The actual, future costs for small installation such as the Bronsbergen one, will only be known when the demo results are out.

Table 1. The basic investment cost of the e-balance system infrastructure in Bronsbergen demo site - from DoW

\begin{tabular}{|c|c|}
\hline Alliander & Total cost: 30000 euro \\
\hline $\begin{array}{c}\text { Other partners (LW; IHP; } \\
\text { UTWE) }\end{array}$ & Total cost: 7000 euro \\
\hline Grand Total: & 37000 euro \\
\hline
\end{tabular}

At this moment, it is established that over 50 users (home users) together with two LVGMU and one MVGMU will be deployed [21]. Smart devices like dish washers or washing machines will be installed in users' homes for free. On the integration level, the APIs of the Whirlpool devices will be tested. The cost and revenue analysis will be prepared and estimated after obtaining the results from the testing. Table 1 presents the basic investment costs planned for the project. As yet, there are no set calculated final costs for its implementation.

\section{Results and difficulties}

The e-balance system will be tested at the demonstrator site in Bronsbergen (The Netherlands).

Up until now, in cooperation with the Increase project, around 50 houses/users have expressed their intention (level of intent) of participating in the test. The deployment of e-balance system is on its way.
The first project participants will receive modern equipment from the Whirlpool company free of charge.

During planning of the e-balance business model, several obstacles have been found [12]. The list of the most important ones is as follows (a lesson learnt during the e-balance and Sustainable Places):

- Main barriers for the implementation/testing of new business models are regulatory constraints.

- A competitive market is the key to the introduction of new business models. No competitive market environment exists as yet; problems with changing regulations, limited possibilities for new data-driven business models.

- Low incentives for existing market actors to encourage them to adopt new business services, as currently any striving for more efficiency does not get rewarded under current legislation.

- It is very important to identify, from the very beginning, the stakeholders (current and potential) involved in each aspect of the proposed solution (project), in order to appoint the system owners and the revenue models scenarios.

- Identification of future energy markets, future actors and their roles is difficult in the unstable EU market.

- Energy companies (DSO/TSO) need to engage more with customers/users. Feedback and engagement with end users is very important to introduce new business models.

- In DR strategies, it is difficult to identify the revenue flow.

- Limited information available for the definition and quantification of the costs and revenues streams.

- A successful replicability of the business models depends on the ability to retrieve data from the sites to be analysed.

- A win-win strategy based on the market rules should be guaranteed in order to avoid being rejected by some stakeholders. Any proposed revenue model should compensate less income with additional savings or higher prices with high-value services.

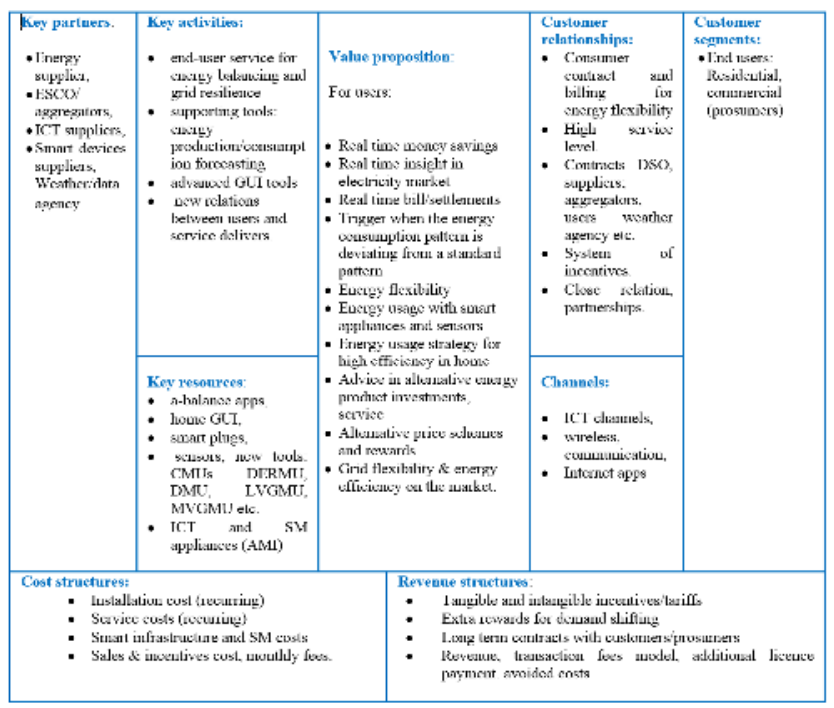

Figure. 3 The Osterwalder's canvas prepared for e-balance BM 
These constraints demonstrate how difficult it is to build a credible business model/BM canvas (Fig.3) for innovative solutions, even in countries where the level of development of a new energy market is much higher than in Poland. The present business model is still being developed and improved accordingly.

\section{Acknowledgment}

This work has been partially funded by the e-balance project (Project Number: 609132), under the European Commission's 7th Framework Programme (FP7SMARTCITIES-2013) and the grant of the Ministry of Science and Higher Education: 3009/7.PR/13/2014/2; (PL). http://www.e-balance-project.eu.

All project's participants: IHP, LessWire: Germany, CEMOSA, UMA: Spain, Alliander, UTWENTE: The Netherlands; ULODZ, OPI: Poland; INOV, EFACEC, EDP: Portugal. All pictures have been prepared by author of this paper.

\section{References}

1. European Parliament and Council Directive 2009/72 / EC of 13 July 2009. Concerning common rules for the internal market in electricity.

2. European Parliament and Council Directive 2012/27 / EU of 25 October 2012. Concerning energy efficiency.

3. The future of the electric grid, An interdisciplinary MIT study 2011,

https://mitei.mit.edu/system/files/Electric_Grid_Full Report.pdf [online: 04.2016]

4. J. Torriti, M. G. Hassan, M. Leach, Energy 35, 4 (2010), http://epubs.surrey.ac.uk/749580/1/DR\%20experien ce\%20in\%20Europe.pdf [online: 04.2016]

5. B.E. Matusiak, et.al.: Energy Management Using the Business Model Approach; European Energy Market, EEM15, Lisbon (Portugal), May 19-22, 2015; doi: 10.1109/EEM.2015.7216612

6. B.E. Matusiak et.al.; Deliverable D2.3 "Market Assessment and Business Models; The e-balance project proceedings; www.e-balance-project.eu; 2015

7. M. Muratori, G. Rizzoni, IEEE Trans. on Pow. Syst. 31, 2 (2016)

8. V. Bakker, Triana: a Control Strategy for Smart Grid, PhD thesis on University of Twente, 2012

9. G. Kotsis, et.al.: Demand Aggregator Flexibility Forecast: Price Incentives Sensivity Assessment; EEM15, European Energy Market International Conference 2015 Lisbon 19-22 May

10. E. Koliou, et.al.: Complexity of demand response integration in European electricity markets, EEM15, European Energy Market International Conference 2015 Lisbon 19-22 May
11. A. Osterwalder, Y. Pigneur, Business Model Generation, Wiley 2012

12. Symposium and proceedings SP15, S. Capato, Business models dimension of EU projects, Savona, Sept. 16-18, 2015 Italy, http://sustainable-places.eu

13. USEF 2013, https://ec.europa.eu/energy/sites/ener/files/document s/xpert_group3_summary.pdf [online: 03.2016]

14. http://www.e-balanceproject.eu/publication_deliverables.html D6.1 [online: 03.2016]

15. S. Hill, How European Utilities can engage customers at a key point to boost NPS, loyalty \& sales; Presentation Opower company on the V Smart Communication \& Technology Forum 11.06.2015 Warszawa

16. B.E. Matusiak, et.al.: How to Balance the Energy Production and Consumption in Energy Efficient Smart Neighbourhoods, MedPower 2014, Athens, ISBN: 978-1-78561-146-9.

17. http://www.e-balanceproject.eu/publication_deliverables.html D4.1 [online: 03.2016]

18. http://www.e-balanceproject.eu/publication_deliverables.html D4.3 [online: 03.2016]

19. http://www.e-balanceproject.eu/publication_deliverables.html D3.1 [online: 03.2016]

20. http://www.e-balanceproject.eu/publication_deliverables.html D3.2 [online: 03.2016]

21. http://www.e-balanceproject.eu/publication_deliverables.html D5.2 [online: 03.2016] 